\title{
25 YEARS OF THE POLISH SOCIETY FOR STEREOLOGY
}

\section{LESZEK WOJNAR}

Institute of Applied Informatics, Faculty of Mechanical Engineering, Cracow University of Technology, Al. Jana Pawla II 37, 31-864 Cracow, Poland

e-mail: leszek.wojnar@gmail.com

(Received November 12, 2013; accepted November 13, 2013)

\begin{abstract}
25 years history of the Polish Society for Stereology is summarized by a person playing active role in the Society from the very beginning till now. Formation and growth of the society is described with emphasize to some milestones in the Society history. This paper is the first attempt to summarize the activity of this scientific organization.
\end{abstract}

Keywords: history, Polish Society for Stereology, stereology.

\section{INTRODUCTION}

25 years is a significant period in professional career of a man as it lasts usually about 40 years. It is also a significant period for a scientific organization, especially in the era of unprecedented changes in science and technology we currently observe. Taking into account the above mentioned remarks I have tried to describe some items from the history of the Polish Society for Stereology. This is a highly emo- tional story as I have been involved in building this Society from scratch. I have written its Statute, next I have been a member of all the executive boards and in the years 1997-2001 I served to the Society as its president. It is my intention not to bother the readers with small problems that we faced during these 25 years. I want just to show some universal values and achievements that gives our Society the right to feel as a partner to the international scientific community.

\section{BACKGROUND AND FIRST STEPS}
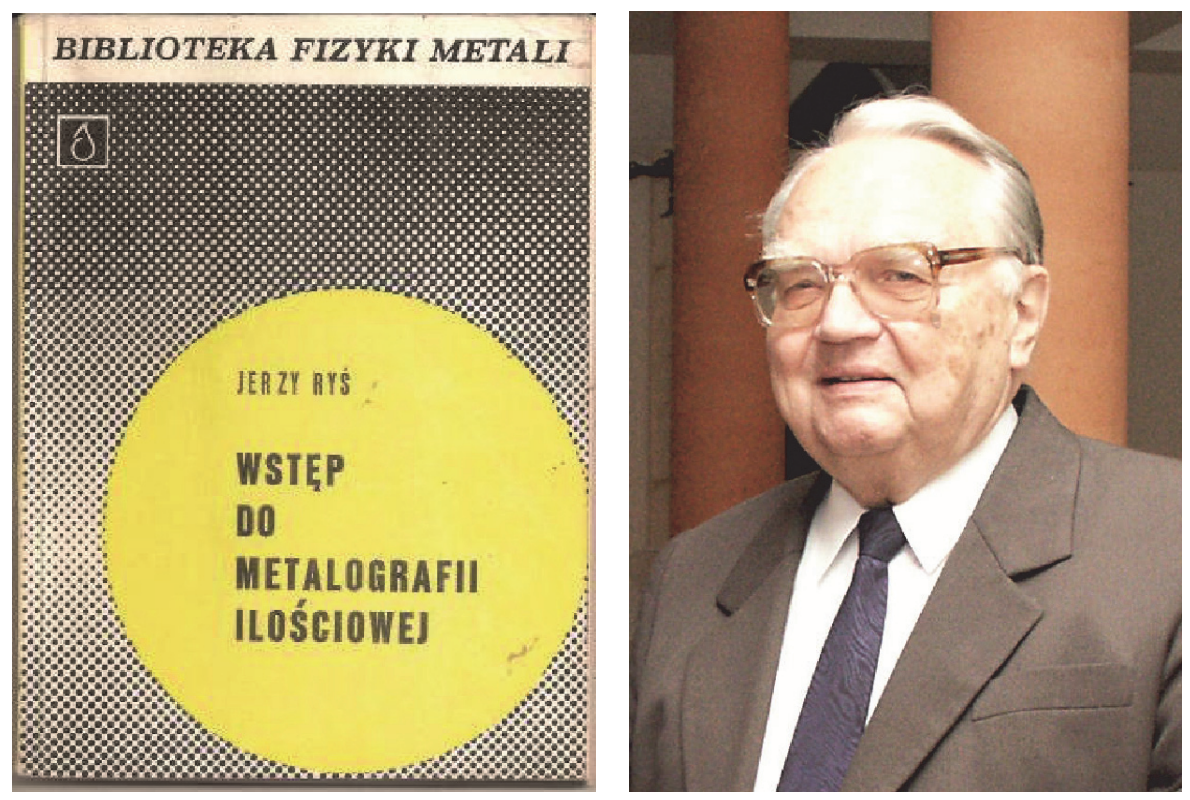

Fig. 1. Cover page of the fundamental work of Jerzy Rys' "Introduction to quantitative metallography", 1970 (left) and prof. Jerzy Ryś at the meeting in Zakopane in 2002 (right). 
Stereological tools have been present in Poland since many years. Some achievements were published even before the Second World War (Bodziony and Hübner, 1987). In 1970 Jerzy Ryś published his "Introduction to quantitative metallography" (Fig. 1). Please, note that in the same year Ervin E. Underwood issued his famous "Quantitative stereology". First attempts to develop a formal organization of Polish stereologists were undertaken in 1981 at the Strata Mechanics Research Institute of the Polish Academy of Sciences. A reference list of Polish publications on stereology or its applications covered 95 papers (Bodziony, 1990). In 1983 the first conference on Stereology in Materials Science took place in Wisła (more on conferences you can find later in this paper) and prof. Jerzy Ryś form the Academy of Mining and Metallurgy established the Group for Stereology at the Committee for Materials Science of the Polish Academy of Sciences. Already in 1978 the Polish Society of Pathologists formed the Section of Mathematical Pathology. Prof. Edward Waniewski initiated in 1984 a series of interdisciplinary conferences on "Morphometric Methods in Biology and Medicine"

In spite of these various activities the political climate in Poland was against formation of any new organization. Finally, after breaking some bureaucratic barriers, the Polish Society for Stereology was founded in 1988 with the aim to facilitate exchange of scientific information among Polish stereologists and their foreign colleagues associated in the International Society for Stereology (Bodziony, 1990). At the first General Assembly of the Society, held in Cracow, Poland on November 28, 1988 Jakub Bodziony was elected as the first President in history of the Polish Society for Stereology.

\section{INTERNATIONAL CONTACTS}

One of the goals of the Polish Society for Stereology in the first period of its activity was development of wider contacts with the International Society for Stereology. These relations begun even before organization of the Society. Prof. Jakub Bodziony was in contact with prof. Miro Kališnik since the congress in Vienna and a wider representation of Polish Scientists participated in the European Congress in Goteborg (Sweden, 1985) and International Congress in Caen (France, 1987). At that time a very important person for our Society was Jean-Louis Chermant who helped many of our colleagues to join the congresses in Caen and next in Freiburg (Germany, 1989) and Irvine (USA, 1991).
Thanks to the existence of the Polish Society for Stereology it was much easier to invite foreign scientists to Poland. The conferences in 1990 and 1994 proved that the scientific contacts were necessary and fruitful. More about the conferences is written in the next chapter.

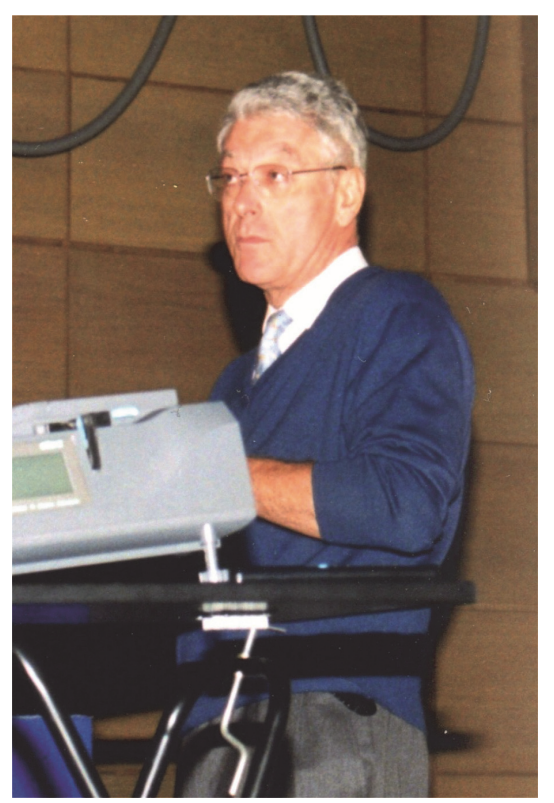

Fig. 2. Jean-Louis Chermant during the STERMAT conference held in Cracow in 2000.

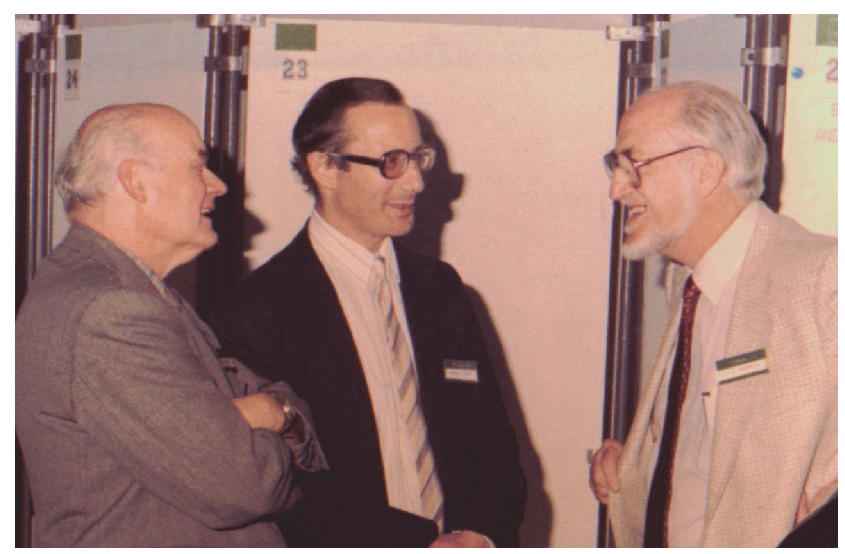

Fig. 3. Vaclav Horalek (Czech Republic), Rodney Coleman (United Kingdom) and Ervin E. Underwood (USA) during the STERMAT'90 conference (1990).

The subtle networks of contacts and often friendship are very important till nowadays when we can easily communicate using the Internet, call phones or international travels without visas. Hopefully, these contacts are still vivid but we should increase them, especially for the younger generation of stereologists. 


\section{ACTIVITIES}

The flagship activity of the Polish Society for Stereology is a series of STERMAT (STEreology in MATerials science) conferences. These conferences started before the Society, in 1983. The third STERMAT conference was held in 1990 and organized already under the auspices of the Polish Society for Stereology and International Society for Stereology. It was, simultaneously, the first STERMAT conference with English as an official conference language.

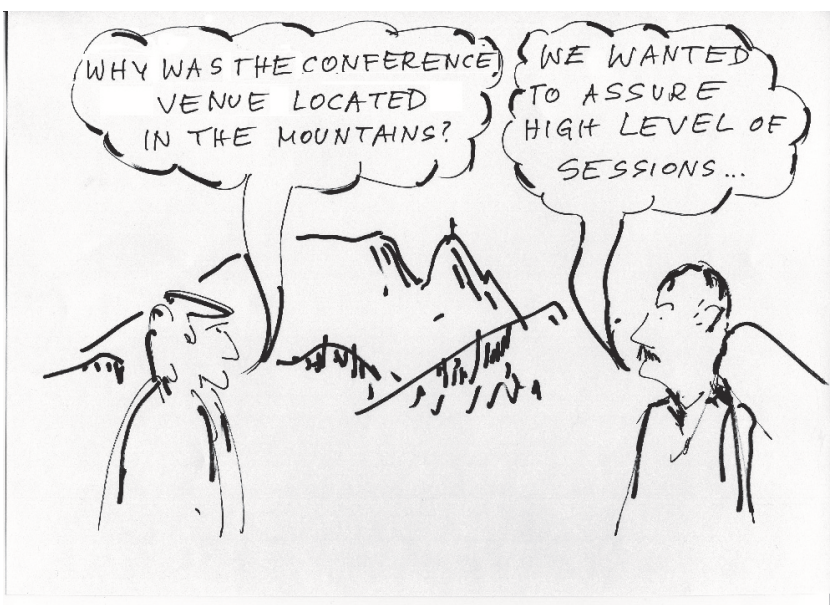

Fig. 4. Most of the STERMAT conferences were held in the Polish mountains.

The name of the conference slightly changed over the years and up to now the following nine conferences have been organized (official names are preserved):

\section{Konferencja}

Stereologia w badaniach materiałoznawczych Kraków-Wisła, maj 1983

\section{Konferencja}

Stereologia w badaniach materiałoznawczych Kraków-Rudy Raciborskie, czerwiec 1986

The Third Conference on

Stereology in Materials Science STERMAT'90

Kraków-Katowice (Szczyrk), October 1990

\section{Intenational Conference on}

Stereology and Image Analysis in Materials Science STERMAT'94

Beskidy Mountains (Wisła), October 3-6, 1994

\section{International Conference on}

the Quantitative Description of Materials

Microstructure Q-MAT'97

Warsaw, April 16-19, 1997

\section{Sixth International Conference on}

Stereology and Image Analysis in Materials Science Cracow, September 20-23, 2000
Seventh International Conference on

Stereology and Image Analysis in Materials Science

Zakopane, May 10-13, 2005

(conference jointly organized with $9^{\text {th }}$ European Congress on Stereology and Image Analysis)

VIII International Conference on

Stereology and Image Analysis in Materials Science STERMAT 2008

Zakopane, September 2-6, 2008

\section{International Conference on}

Stereology and Image Analysis in Materials Science STERMAT 2012

Zakopane, September 3-6, 2012

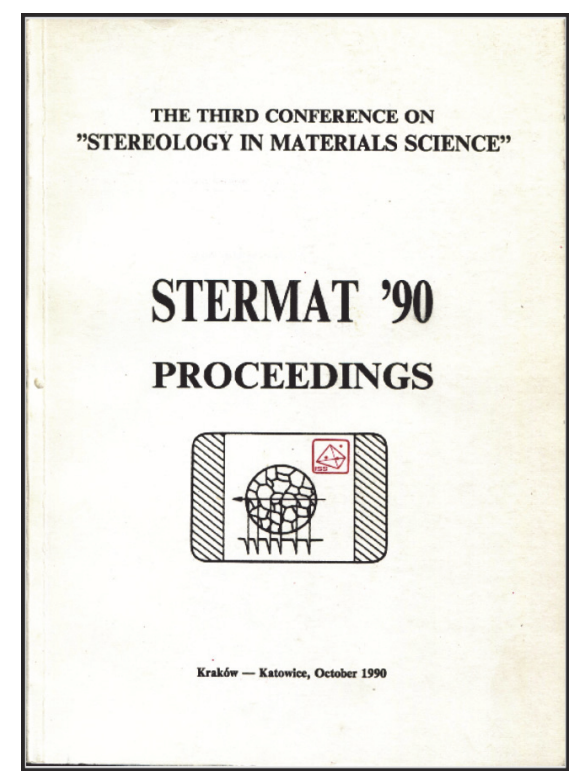

Fig. 5. Proceeding of The third conference on Stereology in materials science STERMAT'90, the first international meeting organized by the Polish Society for Stereology.

The organizing committees of consecutive STERMAT meetings have paid attention to keep the following properties that have been in our opinion essential for the final success:

- The conference venue should assure accommodation of all the participants and sessions in the same place - this makes easier any informal discussion,

- One should assure good food, as hungry man is an angry men and, last but not least,

- The conference proceedings should be available at the beginning of the conference, not a year after it. 

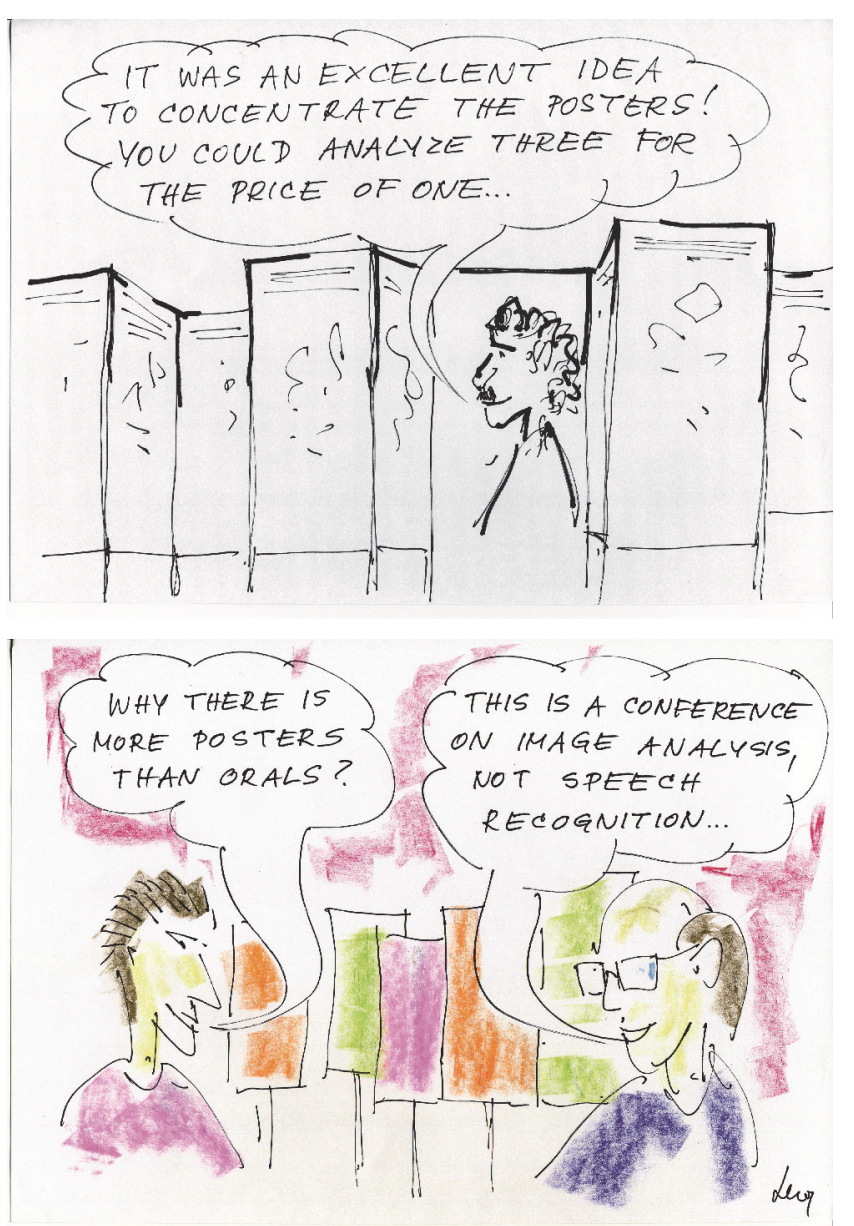

Fig. 6. There were always severe discussions about the role of posters in the conference.

In the conferences from the STERMAT series took part numerous scientists very important for the international scientific family and International Society for Stereology. Among them were (in alphabetical order): David Aboav, Viktor Beneš, Jean-Marc Chaix, Jean-Louis Chermant, Rodney Coleman, Louis M. Cruz-Orive, Ida Eržen, Hans Jurgen Gundersen, Dominique Jeulin, Torsten Mattfeldt, Gerhard Ondraček, Brian Ralph, Ivan Saxl, Jean Serra, Jöelle Riss, Erwin E. Underwood, George VanderVoort and others, not listed here. It demonstrates the value and strength of this series of conferences.

In recent years changes in economic situation of the universities together with the growing value of virtual contacts and electronic publications make organization of conferences more and more difficult. Such a critical situation has been observed last year when the STERMAT conference has been initially waived but finally organized in autumn. We believe, however, that the quality and family-like atmosphere of our meetings will allow to gather a lot of people interested in scientific discussion in real world also during the coming meetings.
There are also other forms of activity of the Polish Society for Stereology. Among them the most valuable is a series of Schools on Image Analysis and Stereology, devoted to training in application of modern techniques in quantitative description of microstructures and organized usually in October. These schools have been also coupled with seminars for young stereologists they can present their works and get opinions from the leading experts in the field. Schools have been also attended by guests from other countries, like, for example Hynek Lauschmann or Bruno Lay who demonstrated the newest software for image analysis. Independently, Dorota Cebula-Kozłowska has organized under the auspices of the Polish Society for Stereology a series of courses devoted to various aspects of structure-properties relationships. One of the leading lecturers during these courses has been George Vander Voort.

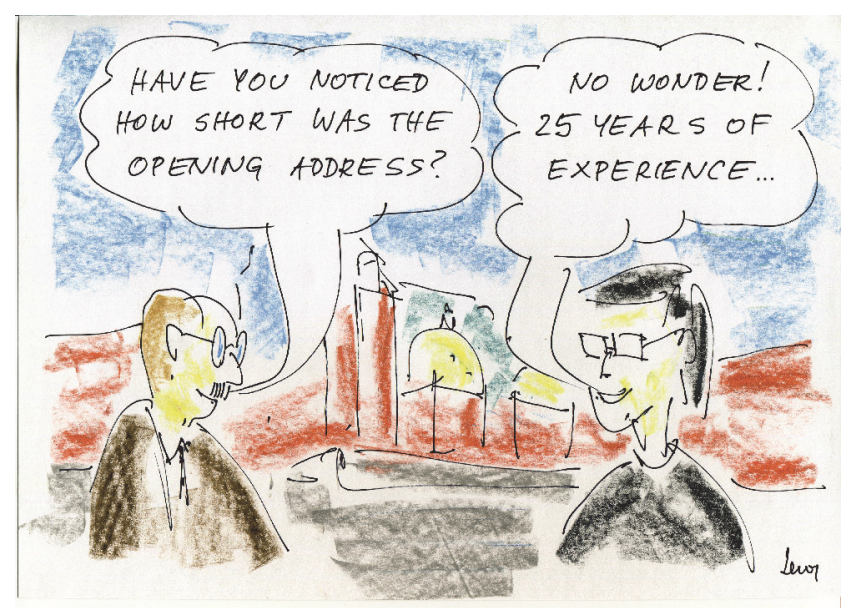

Fig. 7. Everything that happened during the conference could be satirically commented during the closing session.

\section{GOVERING THE SOCIETY}

Since its formation in 1988 the Polish society for Stereology has had 7 Presidents. In general, they keep their position for 4 years. The unofficial rule is that everybody is a president only once - such a rule prevents from many personal conflicts. The following people were in power in the history of the Society:

1988-1992 - Jakub Bodziony, Strata Mechanics Research Institute of the Polish Academy of Sciences,

1992-1996 - Jan Cwajna, Chair of Materials Engineering, Silesian University of Technology,

1996-1999 - Krzysztof J. Kurzydłowski, Institute of Materials Engineering, Warsaw University of Technology, 
1999-2003 - Leszek Wojnar, Institute of Materials Science and Technology of Metals, Cracow University of Technology,

2003-2007 - Jacek Chrapoński, Chair of Materials Engineering, Silesian University of Technology,

2007-2012 - Janusz Szala, Chair of Materials Engineering, Silesian University of Technology,

and since 2012 - Aneta Gądek-Moszczak, Institute of Applied Informatics, Cracow University of Technology.

The Society is multidisciplinary and opened for all the disciplines. However, it is clearly visible that the Presidents of the Society have been associated with scientific institutions oriented towards materials science. This reflects the fact that in Poland stereological methods have been developed mainly in materials science. Biologists or specialists in medicine are active rather in other societies. Obviously, there exists cooperation between specialists in various disciplines, so this is a challenge for the Board of the Society to widen representation of natural sciences in the Society.

It is clear for anybody involved in any activity of larger scale that finances constitute a basis for different projects. Thus, it is essential to have a proper treasurer. This position is kept from the very beginning by the same person - Kazimierz Satora.

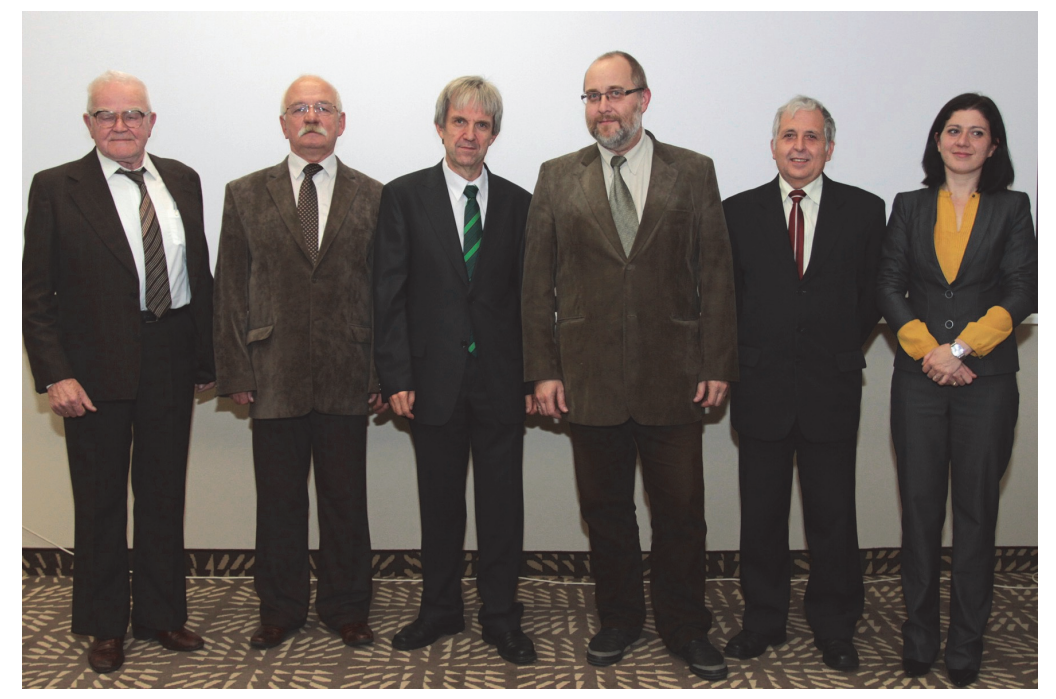

Fig. 8. Presidents of the Polish Society for Stereology during a meeting on November 7, 2013. From left to right: Jakub Bodziony, Jan Cwajna, Leszek Wojnar, Jacek Chrapoński, Janusz Szala, Aneta Gadek-Moszczak. Only one of the past presidents, Krzysztof J. Kurzydtowski is missing.

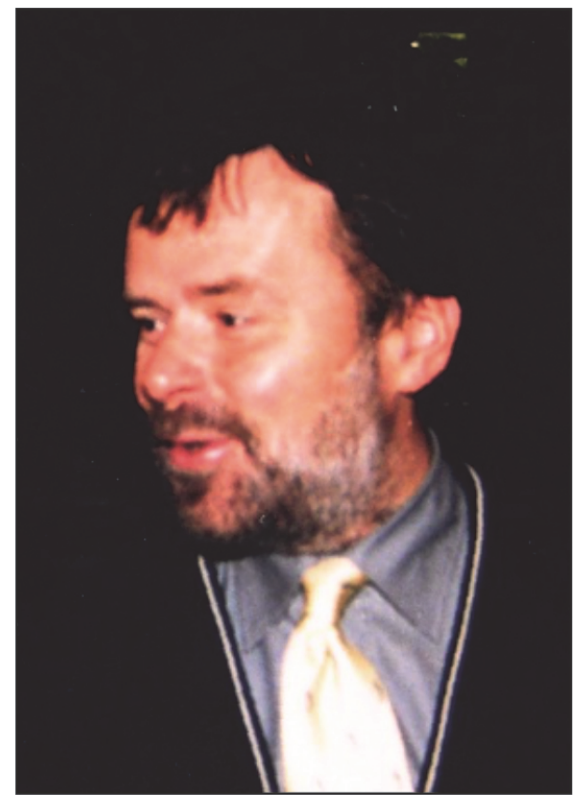

Fig. 9. Krzysztof J. Kurzydlowski, President of the Polish Society for Stereology in the years 1994-1997.

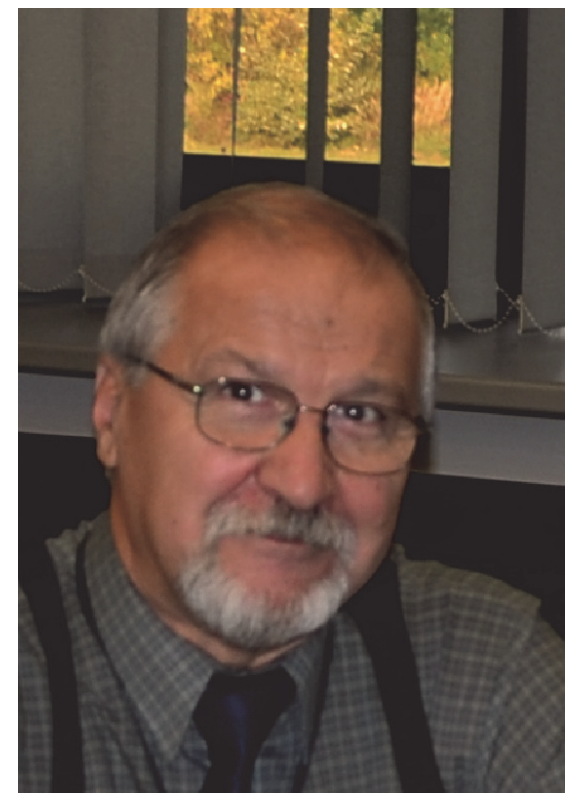

Fig. 10. Kazimierz Satora, treasurer of the Polish Society for Stereology. 


\section{PUBLICATIONS}

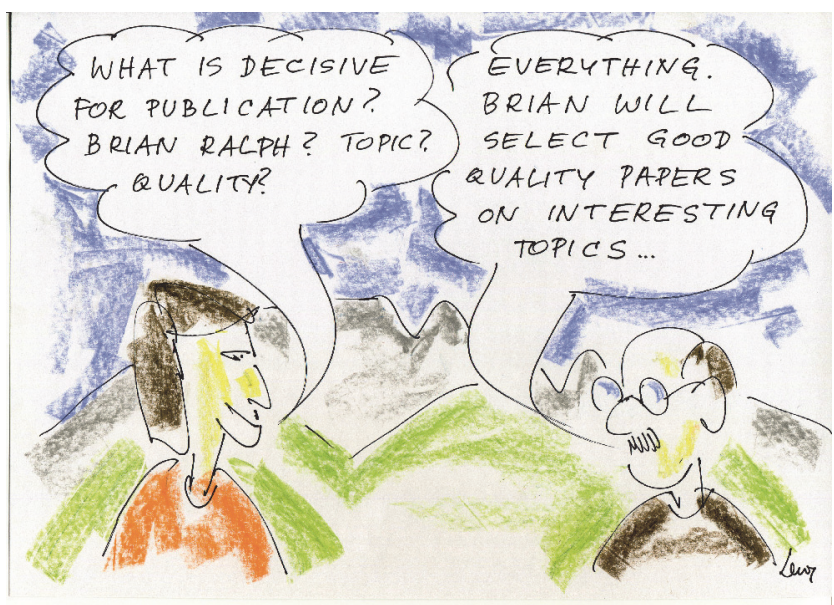

Fig. 11. Selected papers were published after modification in Materials Characterization and Brian Ralph, being the Associate Editor, made final decision if the paper is suitable for publication.

During these 25 years members of the Society have published numerous papers and books. Many of them have been published in Acta Stereologica and, after change of the name, in Image Analysis and Stereology. The most important for the international audience are probably some books or chapters in large monographs. Among such sources of information we can list books by Kurzydłowski and Ralph (1995) and Wojnar (1999) as well as contributions to larger projects (Wojnar and Kurzydłowski, 2000 or Wojnar et al., 2004). An important role has been played, especially in the early nineties, by the STERMAT conference proceedings. Due to good quality of these proceedings it was possible to send them to many libraries and obtain other valuable materials. The list of publications prepared by the members of the Polish Society for Stereology is obviously much longer, but publications in Polish are of less interest for international audience and the list of scientific papers in journals would be simply too long to publish here. There is, however, one book written in Polish that seems to be worth mentioning here. It was published in 2002 by Leszek Wojnar, Krzysztof J. Kurzydłowski and Janusz Szala. Its title is "Praktyka analizy obrazu" (Image analysis in practice). The book was printed in 1000 copies and, after distribution of them, is available since 2006 in electronic form at the digital library of the Cracow University of Technology. Up to date, more than 7000 downloads has been recorded (in addition to the book two files are available, so the book has been downloaded approx. 2500 times).

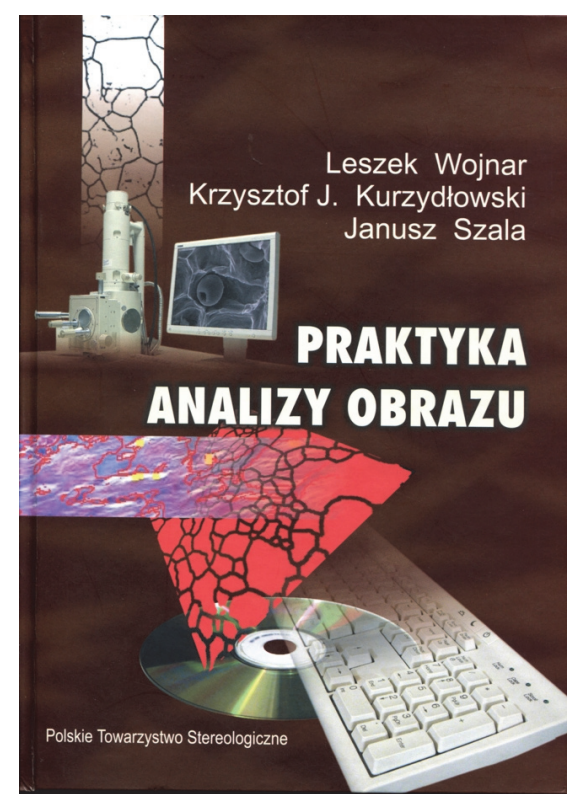

Fig. 12. This book (Image analysis in practice) issued by the Polish Society for Stereology in 2002 and, in electronic form, in 2006 is still a leading textbook on image analysis in Poland.

\section{HUMOR}

A good sense of humor helps to solve difficult problems. Sometimes this is the best, if not the only one, method to relax in situations full of stress. The second day of the STERMAT' 90 conference was just a day of reunification of Germany. Some German colleagues at the conference wanted to serve a glass of wine on this occasion. The atmosphere became very heavy - the ghosts of Second World War were still present in the air... Fortunately, Jean-Louis Chermant found a humorous solution. He asked me to prepare quickly some images. I decided to illustrate the changes in Europe as simple morphological operations in the map of Europe. Massive migration from East Germany through Poland and Czech Republic to West Germany that we observed in 1989-1990 has been interpreted as simple geodesic path. Other changes were interpreted as segmentation, watershed detection or simple closing procedures (see Fig. 13). Jean-Louis Chermant presented it in very light, humorous version and concluded that everything would be O.K. if only we used proper structuring elements. The atmosphere on the conference was rescued.

The above described event was probably the most dramatic one in the history of our meetings. But tens of my humorous drawings accompanied almost all the conferences organized by the Polish Society for 
Stereology. Some of the examples are put in this paper. I do hope that in spite of this activity I am recognized mainly as a scientist rather than an artist.

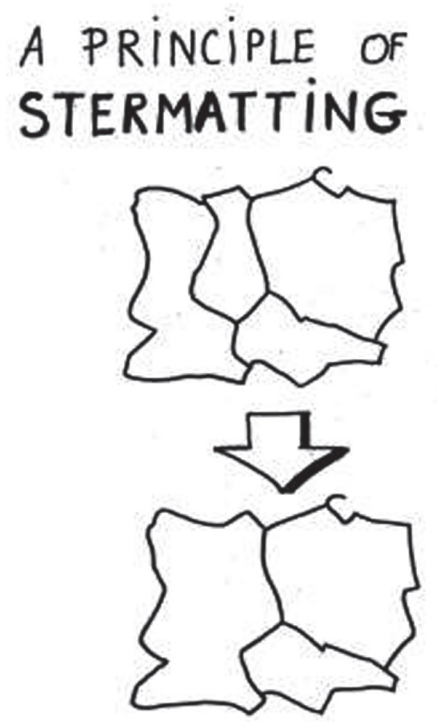

Fig. 13. Reunification of Germany interpreted as morphological operation called "stermatting". The only problem, accordingly to Jean-Louis Chermant, was to use proper structuring element.

\section{PERSPECTIVES}

This is clear that during the last 25 years we have observed dramatic changes in political, economic and technical environment. In 1988 we were still before the era of the Internet and websites and the iron curtain between the East and West in Europe seemed to be very strong. So, the conditions for running a scientific society are nowadays completely different. However, some words of Jakub Bodziony, prepared for STERMAT'90 seem to be still valid and important: "It is necessary to propagate among young people the problems of stereology and to help them in their scientific careers. I do not mean that we are doing nothing in this respect; what I mean is to consolidate our efforts" (Bodziony, 1990).
Before the next STERMAT conference that was held in 1994 Jean-Louis Chermant, who could not join the conference, sent me an opening address in which we could read (this material was not published yet): "And what about borders WITHIN Science? Let me only consider the main field of interest of members of our Society. Of course, Image Analysis, Mathematical Morphology, Stereology are fantastic tools. But perhaps some of you are of the opinion that one of these tools is far more fantastic than the others? If such is the case, I suggest that here again some borders should be abolished. So I am convinced that each of us has got something to teach, and something to learn from the others."

So, some problems have been recognized but remained unsolved since many years. This constitutes new challenges for scientific societies and, due to deep changes in our civilization, requires new solutions. Among these new solutions we can possibly find the need to redefine stereology.

\section{REFERENCES}

Bodziony J, Hübner K (1987). Hugo Steinhaus - an unknown stereologists? Acta Stereol 6(Suppl. II):69-78.

Bodziony J (1990). Polish Stereologists. In: Proceedings of the Third Conference on Stereology in Materials Science STERMAT'90, 1990 Oct 1-4; Kraków-Katowice, Poland, 292-304.

Kurzydlowski KJ, Ralph B (1995). The Quantitative Description of the Microstructure of Materials. Boca Raton: CRC Press.

Wojnar L (1999). Image analysis. Applications in materials engineering. Boca Raton: CRC Press.

Wojnar L, Kurzydłowski KJ (2000). Analysis and Interpretation. In: Practical Guide to Image Analysis. Materials Park, Ohio: ASM International, 145-202.

Wojnar L, Kurzydłowski KJ, Szala J (2004). Quantitative image analysis. In: ASM Handbook, Vol. 9. Metallography and Microstructures. Materials Park, Ohio: ASM International, 403-27. 